\title{
MAPEAMENTO DE COMPETÊNCIAS: Um foco no aluno da Educação a Distância
}

\author{
Patricia Alejandra Behar \\ UFRGS - Porto Alegre - RS - Brasil, Email: pbehar@terra.com.br \\ Ketia Kellen Araújo da Silva \\ UFRGS - Porto Alegre - RS - Brasil; Email: ketiakellen@gmail.com
}

\section{RESUMO:}

O presente artigo tem como objetivo apresentar um mapeamento de competências necessárias aos alunos da Educação a Distância (EAD). O estudo estabelece uma relação entre as competências e os alunos da modalidade a distância, destacando os conhecimentos, as habilidades e as atitudes vinculados a este modelo de ensino. Através da abordagem quali-quanti, por meio do estudo de caso exploratório e único realizou-se o mapeamento através da realização de um curso de extensão, que incluiu entrevistas e questionários. A análise consistiu na avaliação dos dados e no mapeamento final, constituído por um quadro de doze competências, quais são: fluência digital, autonomia, organização, planejamento, administração do tempo, comunicação, reflexão, presencialidade virtual, autoavaliação, auto-motivação, flexibilidade e trabalho em equipe.

PALAVRAS CHAVE: Educação a Distância(EAD), Aluno da EAD, Competências

\section{MAPPING SKILLS: \\ A FOCUS ON THE STUDENT'S OF DISTANCE LEARNING}

\begin{abstract}
The present paper aims at mapping the competences requerid for e-learning students. The study establishes a relationship between skills and students of the distance mode, highlighting the knowledge, skills and attitudes related to this teaching model. Through qualitative and quantitative approach, through the exploratory case study was carried out and only the mapping by performing an extension course, which included interviews and questionnaires. The analysis consisted of an evaluation of the data and the final mapping, consisting of a framework of twelve competencies, which include: digital fluency, autonomy, organization, planning, time management, communication, reflection, presentiality virtual, self-assessment, self-motivation, flexibility and teamwork.
\end{abstract}

KEYWORDS: E-learning. E-learning student. Competences

\section{INTRODUÇÃO}

É indiscutível o avanço que a Educação a Distância (EAD) teve no cenário educacional brasileiro nos últimos anos. Um dos fatores centrais surge com o desenvolvimento de diversas tecnologias, principalmente as Tecnologias da Informação e Comunicação (TIC). Desta forma, a tecnologia gerou uma grande mudança social, na qual cada vez mais a geração que nasce e vive em meio a essas tecnologias desenvolve novas formas de agir, pensar, aprender e ser.

Todas essas transformações tiveram grande impacto na educação, modificando os espaços escolares, os ambientes de aprendizagem e os recursos utilizados para o ensino, bem como o perfil do aluno. 
Compreende-se que tais particularidades, próprias da $\mathrm{EAD}$, requerem que os atores desse processo demonstrem conhecimentos, habilidades e atitudes próprias para esse contexto, os quais podem ser identificados como competências específicas. Assim, tanto para ser aluno quanto para ser docente na EAD é necessário um conhecimento próprio da tecnologia e de suas possibilidades.

Nesse sentido, o presente trabalho versa sobre o estudo de competências básicas essenciais aos alunos da EAD. Para tal, durante o processo de pesquisa foi desenvolvido um objeto de aprendizagem $(\mathrm{OA})^{1}$ intitulado CompMap $^{2}$ (Mapeamento de Competências), que foi aplicado em um curso de extensão com o objetivo de mapear as competências. $^{3}$

Assim, este artigo está dividido da seguinte forma: Inicialmente, é feita uma breve revisão bibliográfica enfocando os temas referentes a competência e os alunos da EAD. $\mathrm{Na}$ sequência é apresentada a pesquisa propriamente dita e por fim as conclusões do trabalho.

\section{AS COMPETENCIAS}

Inicialmente, o termo teve origem no âmbito empresarial, onde a palavra determina uma pessoa capaz de realizar certas atividades com eficiência. Etimologicamente competência nasce do mesmo étimo latino que competição, ambas tem raiz na expressão indo-europeia pot (pet), lançar-se contra ecompetere, encontrar-se no mesmo ponto, estar adequado a, reunir condições (ORIGEM DA PALAVRA, 2005, on-line).

Existe, portanto a proximidade com a área profissional, na qual há exigência de competitividade, desta forma as pessoas não são recursos que a organização consome, utiliza e que produzem custos. Ao contrário, as pessoas constituem um fator de competitividade, da mesma forma que o mercado e a tecnologia, Chiavenatt (2000, p. 20).

Nesse campo, ser profissional, competitivo e competente são expressões ligadas às pessoas mais capacitadas e eficientes, sendo esses os conquistadores dos melhores espaços profissionais. Competência é um saber agir responsável e que é reconhecido pelos outros. Implica saber como mobilizar, integrar e transferir os conhecimentos, recursos e habilidades, num contexto profissional determinad (Le Boterf,1995). Já para Felury e Fleury é uma característica subjacente a uma pessoa que é casualmente relacionada com desempenho superior na realização de uma tarefa ou em determinada situação. (FLEURY; FLEURY, 2001, p. 184).

O conceito de qualificação, para Manfredi (1999), relaciona-se ao modelo tayloristafordista. ${ }^{4}$ Nessa perspectiva, tem-se o mercado de trabalho baseado em um processo de preparação para cargos e funções operacionais. Dessa forma, aqueles que possuem melhor escolaridade ganham posições de liderança, ou seja, níveis hierárquicos mais altos. (Fleury e Fleury 2001, p. 185).

Na perspectiva educacional Gaspar (2004) afirma que o conceito de competência surge a partir de estudos realizados no Canadá, Suíça e Bélgica, no inicio dos anos 90, onde o conceito demonstra ir além de conhecimentos, aptidões ou habilidades. A competência é compreendida como a mobilização desses recursos, que dependerão da experiência pessoal, da formação psicológica, cognitiva e afetiva da pessoa, bem como da situação em que a pessoa está inserida.

\footnotetext{
${ }^{1}$ Neste estudo, entende-se que os objetos de aprendizagem são materiais ou recursos digitais, apresentados isoladamente ou de modo agregado, tendo como finalidade o uso educativo (WILLEY, 2002).

2 "Esse modelo baseava-se na produção de volumes crescentes. ritmo intenso de produção, crescimento sem controle, centralização e especialização do trabalho; O modelo taylorista-fordista sofreu inúmeras críticas, pois o mesmo apresentava problemas quanto à motivação dos colaboradores, comprometimento, criatividade, burocracia e queda de produtividade." (MEIRIM, 2006, on-line).
} 
Ainda hoje, existe muita incerteza sobre a forma como as competências devem ser e estão sendo aplicadas na Educação, pois por vezes demonstram diferentes sentidos, inclusive contraditórios.

Para Perrenoud e Thurler (2002) a competência é aptidão para enfrentar de forma eficaz uma família de situações, mobilizando a consciência de maneira cada vez mais rápida e criativa. Já Zabala e Arnau (2010, p. 37) apresentam o conceito de competência que é adotada neste trabalho sendo a capacidade ou a habilidade para realizar tarefas ou atuar frente a situações diversas de forma eficaz em um determinado contexto. É necessário mobilizar atitudes, habilidades e conhecimentos ao mesmo tempo e de forma interrelacionada.

No Brasil, o conceito direcionado à Educação é incorporado, no ano 1996, através da Lei de Diretrizes e Bases (LDB) $n^{\text {o }}$ 9.394, a qual afirma que o currículo do Ensino Médio deve orientar o desenvolvimento de competências para cidadania.

O parecer CNE/CEB $16 / 99^{5}$, que trata das diretrizes curriculares para a Educação profissional, apresenta a reforma curricular da formação profissional. Aqui o conceito de competências é entendido como: "[...] a capacidade de articular, mobilizar e colocar em ação valores, conhecimentos e habilidades necessários para o desenvolvimento eficiente e eficaz de atividades requeridas pela natureza do trabalho." (BRASIL, 1999a). No ano de 2001, o parecer CNE/CP 9/2001 ${ }^{6}$ acerca da formação de professores, traz como foco central o desenvolvimento de competências. O parecer afirma que: "Não basta a um profissional ter conhecimentos sobre seu trabalho. É fundamental que saiba mobilizar esses conhecimentos, transformando-os em ação" (BRASIL, 2001, p. 29).

O ENEM $^{7}$ (Exame Nacional do Ensino Médio), realizado pelo MEC (Ministério da Educação), desde o ano de 1998 é aplicado a fim de avaliar o desempenho dos estudantes. Essa avaliação tem como base cinco competências. 1- Dominar linguagens; 2- Compreender fenômenos; 3-Enfrentar situações-problema; 4- Construir argumentações; 5- Elaborar propostas.

Percebe-se a utilização exagerada do termo, o que de certa forma gera empregos errôneos, modismos e, por fim, confusões. Santomé (2010) faz uma critica sobre a incorporação de conceitos como meros slogans de modismos, o que acaba desfigurando por completo o seu significado.

Assim, é preciso compreender, portanto, a qual perspectiva a competência está vinculada, buscando contextualizá-la e utilizá-la de forma coerente na Educação, já que a grande problemática no viés educacional é sua associação com o desempenho final do sujeito. Na Educação, há que se pensar em todo o processo de desenvolvimento e mobilização da competência e não apenas no resultado.

A partir dessas diferentes definições de competências, é possível perceber pontos comuns acerca do conceito, tais como:

- Atuação do sujeito em situações novas e complexas;

- Mobilização de recursos, que depende do fato de o sujeito estar ou não disposto a resolver o problema, ou seja, com atitudes determinadas e intenção;

- Domínio de procedimentos na ação a ser realizada;

- A ação deve ser inter-relacionada, pois depende do conjunto de recursos ou domínios do sujeito, não apenas dos conhecimentos, mas da sua experiência, da sua atitude, etc.;

\footnotetext{
${ }_{5}^{5}$ O parecer 16/99 pode ser acessado pelo site: 〈http://portal.mec.gov.br/setec/arquivos/pdf/PCNE_CEB16_99.pdf〉

${ }^{6}$ Disponível em: <http://portal.mec.gov.br/cne/arquivos/pdf/009.pdf>.

Site do ENEM: <http://www.enem.inep.gov.br/enem.php>.
} 
- Os recursos compreendem, portanto, três elementos fundamentais: conhecimentos, habilidades e atitudes.

A análise desses pontos compõe o conceito de competência, sendo necessário compreender os elementos que o compõem: conhecimentos, habilidades e atitudes. Portanto, não é suficiente apenas entender o que é uma competência; é preciso conhecer todo o processo, partindo dos seus elementos como será descrito a seguir.

\section{OS ELEMENTOS}

Os elementos da competência correspondem ao conjunto de recursos que uma determinada pessoa dispõe. Segundo Perrenoud, (1999) “[...] uma competência pressupõe a existência de recursos [...]. Nenhum recurso pertence, com exclusividade, a uma competência, na medida em que pode ser mobilizado por outras."

\section{Conhecimento}

O conhecimento é construído através das relações com o meio. Não é sinônimo de informação ou de saberes. Este estudo entende o conhecimento a partir da visão construtivista de Piaget (1987): "[...] o ponto essencial de nossa teoria é o que o conhecimento resulta de interações entre o sujeito e o objeto que são mais ricas do que aquilo que os objetos podem fornecer por eles." Nesse sentido, tem-se a construção do conhecimento do sujeito sobre o objeto ${ }^{8}$, sendo uma construção, reconstrução em um constante movimento de espiral.

\section{Habilidade}

A habilidade é o elemento da competência que demonstra aquilo que o sujeito sabe e pode aprender. Está relacionada à aplicação produtiva do conhecimento. pode ser construída, por meio da prática, bem como sofrer alterações de acordo com o contexto sociocultural e cognitivo do sujeito.

Em geral a habilidade é menos ampla que uma competência, por isso ela é entendida por muitos autores como um dos elementos da competência. De fato, diferentes habilidades compõem uma ou mais competências, ou seja, elas são utilizadas em diferentes situações.Assim, as habilidades seriam tanto as que apresentam processos mentais/cognitivos como motores e técnicos (Perreound 2001).

\section{Atitude}

Entende-se que são as atitudes que determinam como os indivíduos se posicionam em relação aos outros e aos acontecimentos. É em função delas que se avaliam sentimentos, comportamentos e escolhas. Desta forma, muitos estudos têm demonstrado, exaustivamente, que as atitudes antecedem ao comportamento. É um estado de prontidão organizado pela experiência, que exerce uma influência diretiva e dinâmica sobre as respostas de um indivíduo diante de determinados objetos ou situações (ALPORT apud TRIANDIS, 1971).

Portanto, a atitude é uma tomada de posição e uma predisposição a certas reações, o que interfere na própria maneira de perceber e definir uma opinião, o que é confirmado por Mucchielli (1978).

Diante desse contexto, o processo de desenvolvimento de uma atitude é compreendido como um esquema mental, desenhando o comportamento do processo de interação humana, que se dá pela socialização e comunicação. Nesse processo, a atitude é um dos elementos que resultam no comportamento.

${ }^{8}$ Cf. Becker, 1999, p. 74: "o objeto ou "objectum: o que está em oposição ao sujeito, como diferente, como outro. Objeto é, pois, apenas isso: o não-sujeito." 
Por fim, a atitude determina comportamentos. No entanto, um comportamento depende de outros fatores, e não há limites para as diferentes atitudes que as pessoas podem ter. Assim, a atitude pode ser compreendida como a motivadora da ação.

Assim, a partir da compreensão do contato de competências e seus elementos faz-se necessário compreender quem é o aluno da EAD e suas características.

\section{DELINEANDO O MAPEAMENTO}

O percurso da pesquisa ocorreu no período de dois anos, iniciando por meio do levantamento bibliográfico das temáticas: EAD, perfil do aluno e as competências.

Foi construído ${ }^{9}$ um Objeto de Aprendizagem (OA), intitulado CompMap - Mapeamento de Competências dos alunos da EAD como mostrado na figura 1, a partir do Edital $12^{10}$. $\mathrm{O}$ objeto teve como principal função ser o recurso digital com um conteúdo desenvolvido especificamente para o mapeamento de competências com foco no aluno da EAD.

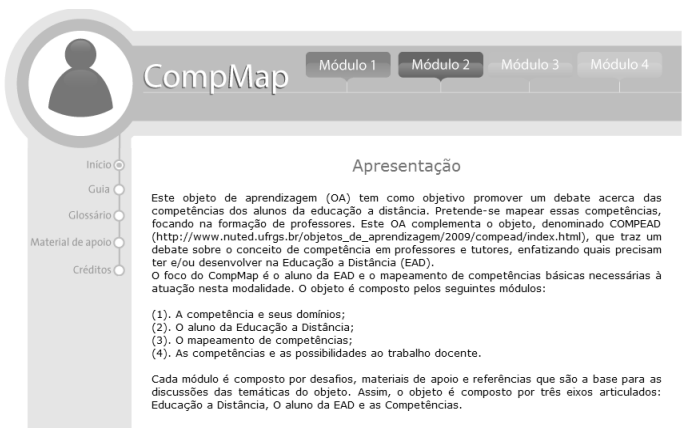

Figura 1 - Tela do Objeto CompMap

No segundo ano o processo de coleta de dados ocorreu através de Questionários, Curso de Extensão e Entrevistas. O curso teve como carga horária total 40 horas, divididas em sete semanas, com três aulas presenciais (início, meio e fim) e quatro à distância. após foram realizadas entrevistas com alguns dos alunos e dos tutores participantes.

\section{MAPEAMENTO DAS COMPETÊNCIAS}

O mapeamento foi realizado a partir da análise de duas categorias criadas a partir dos dados coletados. As categorias foram: 1.0 aluno da EAD e 2. As competências dos alunos da EAD. Destaca-se na categoria o aluno da EAD o perfil mapeado, demonstrando problemas com a tecnologia, com a organização do tempo, a comunicação à distância, entre outras. Percebe-se que, da mesma forma que o aluno na sala de aula precisa de competências que o façam atuar como um estudante, o aluno da EAD também necessita de competências para enfrentar suas dificuldades e descobrir as possibilidades tecnológicas.

O estudante, hoje da EAD, foi esculpido pelo modelo presencial durante todo seu processo de aprendizagem. Enquanto adulto, ele tem pouca familiaridade com a tecnologia, demonstra dificuldades em sentir-se responsável por sua própria aprendizagem e durante muito tempo não foi um produtor de conteúdo, mas sim um reprodutor.

No entanto, atualmente, com todos os recursos digitais, o aluno deve tomar posição sobre sua aprendizagem, desenvolvendo conteúdo, trocando-o e possibilitando que outros o utilizem (COLL; MONEREO, 2010).

9Desenvolvido pelo NUTED com o apoio da Secretaria de Educação a Distância (SEAD) da UFRGS a partir do Edital 12

${ }^{10}$ Edital 12 - SEAD/UFRGS. Destina-se ao financiamento de recursos orçamentários da UFRGS, com o objetivo de apoiar a construção de objetos de aprendizagem e capacitar professores e alunos para o desenvolvimento de materiais educacionais digitais, como forma de fomentar a educação a distância no âmbito da Universidade. 
Assim, é preciso que esse aluno construa uma nova identidade, a de aluno virtual. Para isso, se faz necessário remodelar o que já foi elaborado durante anos de um processo educacional em situações presenciais. Tal processo não é apenas uma causa ou um produto da interação, mas deverá ser uma transformação constante.

Assim, para desenvolver essa identidade EAD, são necessários três pontos fundamentais, conforme a Figura 2:1. Atuação estratégica: organização do tempo, formas de comunicação, disposição, motivação para a temática, etc.; 2. Compreensão das características do grupo, bem como das tarefas, dos objetivos do curso e do contexto em que está inserido; e, por fim, 3. Condições tecnológicas, que se referem à conexão do aluno, à utilização das ferramentas e à familiaridade com a tecnologia.

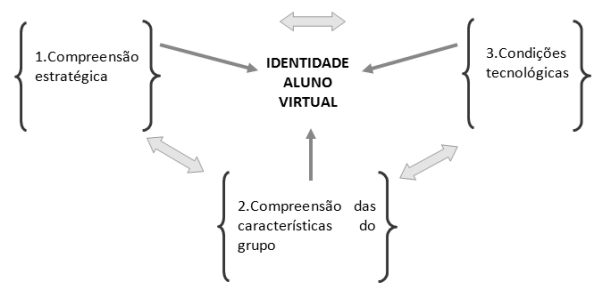

Figura 2-Representação da Identidade do Aluno Virtual Fonte: Construído pelas autoras

Inicialmente, o estudante pode levar para o mundo virtual suas experiências presenciais, assim como a compreensão das estratégias, das características e do aparato tecnológico. O aluno poderá começar a criar uma espécie de hibridização ou blendedlearning (TORI, 2010).

Essa convergência entre suas experiências presenciais e virtuais irá desencadear seu estilo e sua forma de atuar em cada situação, ora no presencial e ora no virtual, conforme Figura 2.

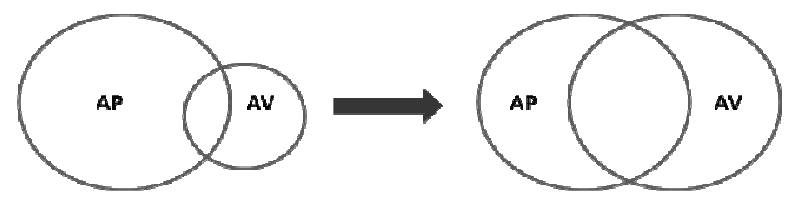

Figura 2- Processo de Hbridização entre Aprendizagem Presencial (AP) $e$ Aprendizagem Virtual (AV)

Fonte: Baseado em Tori, 2010.

Para concluir, pode-se dizer que o perfil desse aluno EAD é composto por três contextos/dimensões interligadas, conforme Figura 4, que são: social /familiar, profissional e acadêmico. A tecnologia destaca-se como um contexto transversal, que permeia todos os outros, já que está presente no cotidiano desse sujeito. Entretanto, ela não é um recurso com o qual esse aluno esteja familiarizado, sendo um contexto em construção e que, por meio das experiências e do tempo, sofrerá transformações com resultados diferentes em cada sujeito.

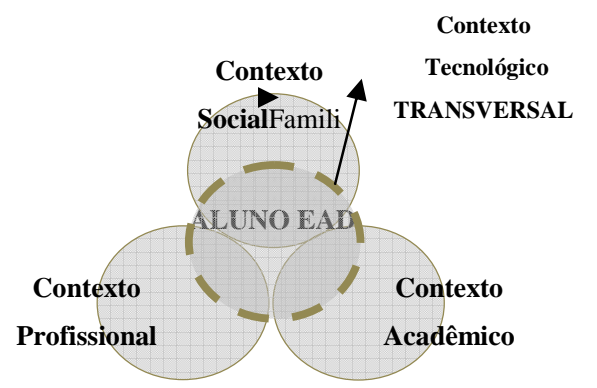


Figura 4-O Contexto do Aluno da EAD

Fonte: Construído pela autora

Em cada um dos contextos, o aluno poderá atuar de uma forma, assim como necessitará de competências que, em alguns casos, coexistem em mais de um contexto, sendo organizadas e reorganizadas quanto necessário. No entanto, esses espaços não são desarticulados, mas estão sempre em contato, interligados como a figura mostra.

A partir do levantamento de dados e organização do perfil foi possível apresentar e elencar com mais clareza quais as competências necessárias para esse aluno.

\section{AS COMPETENCIAS}

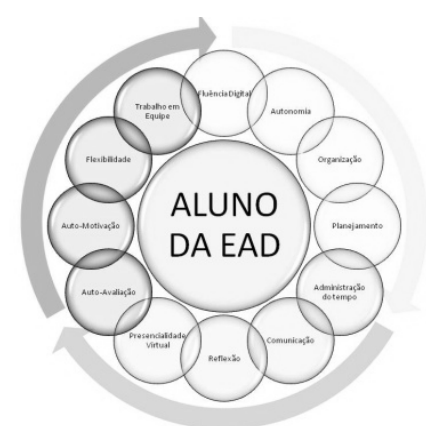

Figura 5-Doze Competências do Aluno da EAD

Figura 5 apresenta a organização das doze competências. Através dos resultados é possível perceber que existe uma graduação das competências, no qual a figura representa através das setas. Esta análise baseada em graus de dificuldade foi possível por meio das falas dos alunos. 


\begin{tabular}{|l|l|l|l|l|}
\hline Competência & ADMINISTRAÇÃO DO TEMPO & Competência & REFLEXÃO \\
\hline Descrição & $\begin{array}{l}\text { É pautada no cumprimento da } \\
\text { agenda, conciliar atividades de } \\
\text { compromissos para a gestão das } \\
\text { atividades, atingindo as prioridades, } \\
\text { metas e objetivos. }\end{array}$ & $\begin{array}{l}\text { Descrição } \\
\text { Está baseada na abstração para refletir e } \\
\text { e modos de agir. }\end{array}$ \\
\hline Conhecimentos & $\begin{array}{l}\text { Prazos, formas de organização, } \\
\text { autoconhecimento. }\end{array}$ & Conhecimentos atividades \\
\hline
\end{tabular}

\begin{tabular}{|c|c|c|c|}
\hline Competência & FLUÊNCIA DIGITAL & Competência & ORGANIZAÇÃO \\
\hline Descrição & $\begin{array}{l}\text { Está ligada à utilização da } \\
\text { tecnologia de modo que o sujeito } \\
\text { sinta-se } \\
\text { ativo/participante dos avanços } \\
\text { tecnológicos. A fluência possibilita } \\
\text { não só o uso, mas também a criação } \\
\text { e produção de conteúdos/materiais. }\end{array}$ & Descrição & $\begin{array}{l}\text { Relaciona-se com a ordenação, } \\
\text { estruturação e sistematização de } \\
\text { atividades, materiais e grupos. }\end{array}$ \\
\hline Conhecimentos & $\begin{array}{l}\text { Teórico/tecnológico sobre as } \\
\text { ferramentas. }\end{array}$ & Conhecimentos & $\begin{array}{l}\text { Ter autoconhecimento, planejar, } \\
\text { conhecer os prazos. }\end{array}$ \\
\hline Habilidades & Mexer, buscar, selecionar, produzir. & Habilidades & $\begin{array}{l}\text { Criar estratégias, sistematizar, ordenar e } \\
\text { classificar. }\end{array}$ \\
\hline Atitudes & $\begin{array}{l}\text { Ter iniciativa para buscar inovações } \\
\text { e sempre se manter atualizado. }\end{array}$ & Atitudes & $\begin{array}{l}\text { Ser engajado, estar envolvido, ser } \\
\text { proativo, tomar decisões, ter persistência. }\end{array}$ \\
\hline Competência & AUTONOMIA & Competência & PLANEJAMENTO \\
\hline Descrição & $\begin{array}{l}\text { Para Piaget, autonomia significa ser } \\
\text { governado por si mesmo. É o } \\
\text { oposto de heteronomia, que } \\
\text { significa que uma pessoa é } \\
\text { governada por outra pessoa. }\end{array}$ & Descrição & $\begin{array}{l}\text { Baseado no estabelecimento de } \\
\text { prioridades, metas e objetivos. Em } \\
\text { educação, consideram-se também as } \\
\text { condições necessárias para criar } \\
\text { situações e aplicar estratégias de } \\
\text { aprendizagem. }\end{array}$ \\
\hline Conhecimentos & $\begin{array}{l}\text { Normas sociais e culturais, valores } \\
\text { morais, conhecimentos sobre ética. }\end{array}$ & $\begin{array}{l}\text { Conhecimento } \\
\mathrm{s}\end{array}$ & $\begin{array}{l}\text { Tipos de planejamento, contexto, } \\
\text { potencialidades, fragilidades, público } \\
\text { (se houver). }\end{array}$ \\
\hline Habilidades & 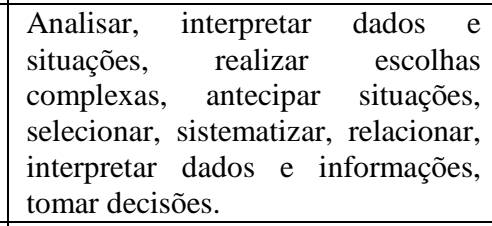 & Habilidades & Sistematizar, avaliar, analisar. \\
\hline Atitudes & $\begin{array}{l}\text { Ter autocontrole e ser responsável, } \\
\text { ser autocrítico, ser proativo, ser } \\
\text { compromissado e ser ético. }\end{array}$ & Atitudes & $\begin{array}{l}\text { Ser proativo, ser objetivo, ser } \\
\text { metódico. }\end{array}$ \\
\hline Habilidades & $\begin{array}{l}\text { Utilizar o tempo de forma eficiente, } \\
\text { dar limites, estabelecer prazos, } \\
\text { delimitar prioridades, ordenar as } \\
\text { ações, identificar objetivos. }\end{array}$ & Habilidades & $\begin{array}{lcc}\text { Analisar } & \text { e } & \text { interpretar } \\
\text { dados/fatos/situações. } & \end{array}$ \\
\hline Atitudes & $\begin{array}{l}\text { Ser proativo, ser objetivo, ser } \\
\text { focado. }\end{array}$ & Atitudes & $\begin{array}{l}\text { Ser proativo, ser crítico, ser ponderado, } \\
\text { ter autodidaxia, ter autocontrole. }\end{array}$ \\
\hline Competência & COMUNICAÇÃ̃O & Competência & PRESENCIALIDADE VIRTUAL \\
\hline Descrição & $\begin{array}{l}\text { Está fundamentada na clareza e na } \\
\text { objetividade da expressão oral, } \\
\text { gestual e escrita. }\end{array}$ & Descrição & $\begin{array}{l}\text { Tem relação com a presença no ambiente } \\
\text { virtual através da interação com os colegas } \\
\text { e da realização das atividades. }\end{array}$ \\
\hline Conhecimentos & $\begin{array}{lcr}\text { Norma culta } & \text { da } & \text { língua, } \\
\text { compreender } & \text { regras } & \text { de } \\
\text { comportamento, } & \text { formas } & \text { de } \\
\text { comunicação, público/receptores }\end{array}$ & Conhecimentos & $\begin{array}{l}\text { Sobre o ambiente virtual e suas } \\
\text { ferramentas, formas de comunicação e } \\
\text { prazos. }\end{array}$ \\
\hline Habilidades & $\begin{array}{l}\text { Escrita de forma clara, objetiva e } \\
\text { coerente, interpretar mensagens } \\
\text { recebidas, como impostar a voz, } \\
\text { articular as palavras, usar } \\
\text { vocabulário adequado. }\end{array}$ & Habilidades & $\begin{array}{l}\text { Utilizar as ferramentas do ambiente } \\
\text { virtual de forma eficiente para } \\
\text { comunicação e envio de atividades. }\end{array}$ \\
\hline Atitudes & $\begin{array}{l}\text { Ser expressivo, ser empático, ser } \\
\text { cauteloso, ser articulado. }\end{array}$ & Atitudes & $\begin{array}{l}\text { Ser proativo, ser analítico, } \\
\text { discernimento, ser participativo. }\end{array}$ \\
\hline
\end{tabular}




\begin{tabular}{|c|c|c|c|}
\hline Competência & AUTOAVALIAÇÃO & Competência & FLEXIBILIDADE \\
\hline Descrição & $\begin{array}{l}\text { Trata-se da compreensão acerca do } \\
\text { desenvolvimento do próprio } \\
\text { processo de aprendizagem, a fim de } \\
\text { colaborar ou avaliar as atividades } \\
\text { propostas. }\end{array}$ & Descrição & $\begin{array}{l}\text { Consegue lidar com diferentes } \\
\text { necessidades, examinando e interpretando } \\
\text { as possibilidades de ações, bem como } \\
\text { mudanças de opinião e atitudes. }\end{array}$ \\
\hline Conhecimentos & $\begin{array}{l}\text { Conhecer suas necessidades } \\
\text { aprendizagem, conhecer } \\
\text { processo de aprendizagem e as } \\
\text { formas de avaliação. }\end{array}$ & Conhecimentos & $\begin{array}{l}\text { Sobre relacionamento interpessoal, saber } \\
\text { lidar com as diferenças socioculturais. }\end{array}$ \\
\hline Habilidades & $\begin{array}{l}\text { Analisar o processo de } \\
\text { aprendizagem, } \\
\text { atividades, mediar, levar ematizar } \\
\text { consideração suas particularidades. }\end{array}$ & Habilidades & $\begin{array}{l}\text { Identificar situações, analisar possíveis } \\
\text { soluções, contornar situações. }\end{array}$ \\
\hline Atitudes & $\begin{array}{l}\text { Ter autocontrole, ser critico, ser } \\
\text { atualizado, ter acolhimento. }\end{array}$ & Atitudes & $\begin{array}{l}\text { Ser ético, ser responsável, saber mudar de } \\
\text { postura. }\end{array}$ \\
\hline Competência & AUTO-MOTIVAÇÃO & Competência & TRABALHO EM EQUIPE \\
\hline Descrição & $\begin{array}{l}\text { Estabelece as condições para } \\
\text { manter a motivação entre pares e } \\
\text { consigo mesmo, sendo um } \\
\text { facilitador dos processos. Da } \\
\text { mesma forma, ser capaz de acolher } \\
\text { as dificuldades do outro, } \\
\text { incentivando-o a permanecer e } \\
\text { concluir uma atividade, sendo ativo } \\
\text { e participativo. Ser capaz de lidar } \\
\text { com as próprias dificuldades. }\end{array}$ & Descrição & $\begin{array}{l}\text { O trabalho em equipe contempla as } \\
\text { relações intra e interpessoal, as quais } \\
\text { permitem ao sujeito expressar e } \\
\text { comunicar, de modo adequado, seus } \\
\text { sentimentos, desejos, opiniões e } \\
\text { expectativas. Além disso, evidencia } \\
\text { condutas interpessoais, destreza para } \\
\text { interagir com outras pessoas de forma } \\
\text { socialmente aceitável e valorizada, } \\
\text { podendo, assim, trazer benefícios aos } \\
\text { participantes nos momentos de interação. } \\
\text { Esses elementos podem, ainda, ser } \\
\text { complementados sob a ótica afetiva, isso } \\
\text { porque a complexidade das relações } \\
\text { sociais também requer a capacidade de } \\
\text { perceber e fazer distinções no humor, nas } \\
\text { intenções, nas motivações e nos } \\
\text { sentimentos de outras pessoas. }\end{array}$ \\
\hline Conhecimentos & $\begin{array}{l}\text { Autoconhecimento, } \begin{array}{r}\text { conhecimento } \\
\text { sobre o outro, mecanismos } \\
\text { motivacionais. }\end{array} \\
\end{array}$ & Conhecimentos & $\begin{array}{l}\text { Tipos de equipes, saber parcial das áreas } \\
\text { que compõe a equipe. }\end{array}$ \\
\hline Habilidades & $\begin{array}{l}\text { Discernir, criticar, analisar, } \\
\text { enfrentar obstáculos. }\end{array}$ & Habilidades & $\begin{array}{l}\text { Adequar ações intra e interpessoais, criar } \\
\text { estratégias, articular a comunicação com } \\
\text { os sujeitos. Identificar perfil e } \\
\text { necessidades da equipe em que está } \\
\text { inserido, saber trabalhar em clima de } \\
\text { equidade, articular conflitos, negociar, } \\
\text { comunicar, colaborar, cooperar, ser capaz } \\
\text { de se adaptar a situações novas, conduzir } \\
\text { diferentes situações. }\end{array}$ \\
\hline Atitudes & $\begin{array}{l}\text { Ter autoestima, ter autoconfiança, } \\
\text { ter disposição, ser participativo, ser } \\
\text { engajado, ser acolhedor, ser aberto } \\
\text { a trocas, ser empático, ser receptivo, } \\
\text { colocar-se no lugar do outro. }\end{array}$ & Atitudes & $\begin{array}{l}\text { Ser preocupado em alcançar os objetivos } \\
\text { comuns à equipe, ser flexível, ser aberto a } \\
\text { críticas e sugestões, saber ouvir o outro, } \\
\text { ser colaborativo, ser cooperativo. }\end{array}$ \\
\hline
\end{tabular}

\section{CONCLUSÕES}

O foco deste trabalho foi relacionar os estudos acerca das competências com a EAD, buscando identificar nos alunos dessa modalidade as competências que poderão auxiliálos no processo de aprendizagem. O objetivo final foi organizar um mapeamento dessas competências e seus elementos. O estudo iniciou com a pesquisa bibliográfica acerca da EAD, o aluno da EAD e as competências. Ao analisar o perfil do aluno dessa modalidade, percebeu-se a necessidade de novas possibilidades educacionais. Assim, as competências vêm ao encontro dessas condições, buscando, através do aluno e de seus 
formadores, respostas a fim de propor ações e mudanças, principalmente nos desafios enfrentados pelos alunos que iniciam seus estudos na EAD. Nesse sentido, cada vez mais são necessários sujeitos que tenham competências suficientes para realizar adequadamente a gestão da sua própria aprendizagem, buscando, assim, aprender com autonomia.

No decorrer de um curso a distância, exige-se do aluno muita organização e flexibilidade. Assim, entender quais são as competências e os elementos que podem facilitar o processo de aprendizagem do aluno parece ser essencial aos sujeitos que participam desse processo.

Portanto, o aluno, sujeito desse processo, também precisa compreender que essa modalidade requer conhecimentos, habilidades e atitudes diferentes das do ensino presencial, o que influencia sua forma de atuar.

Ser aluno é um oficio, pois se aprende a ser e agir de acordo com atribuições. Para Perrenoud (1995), decididamente, o aluno exerce um gênero de trabalho determinado, reconhecido ou tolerado pela sociedade, e do qual retira os seus meios de sobrevivência. Portanto, requer atitudes que deem conta dessas mudanças sociais, sendo um sujeito ativo no seu processo de aprendizagem, participando das discussões, refletindo, dando opiniões e questionando. Seu desenvolvimento depende de suas vivências e experiências, pois, enquanto profissional, se deparará com questões complexas, sobre as quais necessitará realizar uma reflexão mais elaborada, partindo de seus conhecimentos, atitudes e habilidades. Acredita-se que o presente trabalho, desenvolvido na dissertação de mestrado da autora, (Silva, 2012) poderá trazer reflexões para as práticas a distância, bem como novas formas de ensinar e aprender.

\section{REFERENCIAS}

AMANTE, Lúcia; MORGADO, Lina. Metodologia de concepção e desenvolvimento de aplicações educativas: o caso dos materiais hipermídia. Discursos: língua, cultura e sociedade, Lisboa, v. 3, n. especial, p. 27-44, jun. 2001.

Parecer CNE/CEB n ${ }^{\circ}$ 16/99. Trata das Diretrizes Curriculares Nacionais para a Educação

Profissional deNível Técnico. Brasília: Ministério da Educação, 1999a. Disponível em: <http://portal.mec.gov.br/setec/arquivos/pdf/PCNE_CEB16_99.pdf>. Acesso em: 14 agos. 2012.

. Parecer CNE/CP 9/2001. Diretrizes Curriculares Nacionais para a Formação de Professores da Educação Básica, em nível superior, curso de licenciatura, de graduação plena. Brasília: Ministério da Educação, 2001. Disponível em: 〈http://portal.mec.gov.br/cne/arquivos/pdf/009.pdf〉. Acesso em: 10 agos. 2012.

. Referenciais de Qualidade para Educação Superior a Distância. Brasília: Ministério da Educação,

Secretaria de Educação a Distância, 2007. Disponível em:
<http://portal.mec.gov.br/seed/arquivos/pdf/referenciaisead.pdf>. Acesso em: 10 agos. 2012.

BRONCKART, Jean-Paul; DOLZ, Joaquim. A Noção de Competência: qual é a sua pertinência para o estudo da aprendizagem das ações de linguagem. In: DOLZ, Joaquim; OLLAGNIER, Edmée (Org.). O Enigma da Competência em Educação. Tradução de Cláudia Schilling. Porto Alegre: Artmed, 2004. p. 29-44.

CHIAVENATO, Idalberto. Introdução à Teoria Geral da Administração. 6. ed. Rio de Janeiro: Campus, 2000.

COLL, Cesar; MONEREO, Carles. Educação e Aprendizagem no século XXI: novas ferramentas, novos cenários, novas finalidades. In:___.Psicologia da Educação Virtual: aprender e ensinar com as tecnologias da informação e da comunicação. Porto Alegre: Artmed, 2010. p. 15-46.

FLEURY, Afonso; FLEURY, Maria Tereza. Construindo o conceito de competência. 2001. Disponível em: <http://www.scielo.br/pdf/rac/v5nspe/v5nspea10.pdf>. Acesso em: 25 julho. 2012.

GASPAR, Maria Ivone. Competências em Questão: Contributo para a Formação de Professores. Portugal, $2004 . \quad$ Disponível $\quad$ em: ab.pt/bitstream/10400.2/158/1/Discursos\%E2\%80\%93Forma\%C3\%A7\%C3\%A3o\%20de\%20Professores 55-71.pdf>. Acesso em: 23 agos. 2012.

GUIMARÃES, Luciano Rosa Sathler. O Aluno e a Sala de aula virtual In:LITTO, Fredric M.; FORMIGA, Marcos (Org.). Educação a Distância: o estado da arte, volume 2 . São Paulo: Pearson Education do Brasil, 2011.

LE BOTERF, Guy. De lacompétence - essaisurunattracteurétrange. In: Leséditions d'organisations. Paris: QuatrièmeTirage, 1994.

V. $10 \mathrm{~N}^{\circ}$ 3, dezembro, 2012 
Habilidades e Competências no Século XXI. Mediação, 2010.

DOLZ, Joaquim; OLLAGNIER, Edmée. A Noção de Competência: necessidade ou moda pedagógica. In: (Org.). O Enigma da Competência em Educação. Tradução de Cláudia Schilling. Porto Alegre: Artmed, 2004a.p. 9-23.

Porquê construir competências a partir da escola?, Porto, ASA. 2001.

TRIANDIS, Harry. Attitudeandattitudechange. New York: JonhWiley, 1971

Pozo e Monereo(2010

PIAGET, Jean. O Nascimento da Inteligência na Criança. Suíça: Editora Guanabara. 1987.

PRENSKY, Mark. Digital Natives, Digital Immigrants. In: OntheHorizon. NCB University Press, n. 5, v. 9. 2001.

SANTOMÉ, Jurjo Torres. Evitando o debate sobre a cultura no sistema educacional: Como ser competente sem conhecimento. In: SACRISTÁN, José Gimeno (Org.). Educar por Competências: o que há de novo? Porto Alegre: Artmed, 2010, p. 161-197.

YIN, Robert K. Estudo de Caso: planejamento e métodos. 3. ed. Porto Alegre: Bookman Companhia Ed, 2005.

TORI, Romero. Educação sem Distância: as tecnologias interativas na redução de distâncias em ensino e aprendizagem. São Paulo: Editora Senac São Paulo, 2010.

THURLER, Monica Gather. As competências para ensinar no século XXI: a formação dos professores e o desafio da avaliação. Trad.: Cláudia Schilling; Fátima Murad. Porto Alegre: Artmed, 2002.

ZABALA, Antoni; ARNAU, Laia. Como aprender e ensinar competências. Porto Alegre: Artmed, 2010.

SILVA, Araújo da, KetiaKellen. MAPEAMENTO DE COMPETÊNCIAS:um foco no aluno da Educação a Distância, Silva 2012. 185 f. 